\section{OPEN ACCESS}

Edited by:

Marcello Dallio,

University of Campania Luigi

Vanvitelli, Italy

Reviewed by:

Ruggiero Francavilla, University of Bari Aldo Moro, Italy

Fabio Campos,

Universidade de São Paulo, Brazil

*Correspondence: Juan Gómez-Salgado jgsalgad@gmail.com

Specialty section: This article was submitted to

Gastroenterology,

a section of the journal

Frontiers in Medicine

Received: 16 January 2021 Accepted: 31 May 2021

Published: 25 June 2021

Citation:

Rodríguez-Padilla Á,

Morales-Martín G, Pérez-Quintero R,

Rada-Morgades R, Gómez-Salgado J

and Ruiz-Frutos C (2021) Diversion

Colitis and Probiotic Stimulation:

Effects of Bowel Stimulation Prior to lleostomy Closure.

Front. Med. 8:654573.

doi: 10.3389/fmed.2021.654573

\title{
Diversion Colitis and Probiotic Stimulation: Effects of Bowel Stimulation Prior to Ileostomy Closure
}

Ángela Rodríguez-Padilla ${ }^{1}$, Germán Morales-Martín ${ }^{1}$, Rocío Pérez-Quintero ${ }^{2}$, Ricardo Rada-Morgades ${ }^{2}$, Juan Gómez-Salgado ${ }^{3,4 *}$ and Carlos Ruiz-Frutos ${ }^{3,4}$

${ }^{1}$ Department of General Surgery, Infanta Elena University Clinical Hospital, Huelva, Spain, ${ }^{2}$ Department of General Surgery, Juan Ramón Jiménez University Clinical Hospital, Huelva, Spain, ${ }^{3}$ Department of Sociology, Social Work and Public Health, Faculty of Labour Sciences, University of Huelva, Huelva, Spain, ${ }^{4}$ Safety and Health Postgraduate Programme, Universidad Espiritu Santo, Guayaquil, Ecuador

Background: Diversion colitis is a non-specific inflammation of a defunctionalised segment of the colon after a temporary stoma has been performed. This inflammation is associated with a change in the colonic flora.

Aim: To evaluate the efficacy and safety of preoperative stimulation of the efferent loop with probiotics prior to closure of the protective ileostomy in patients operated on colorectal carcinoma and its effect on diversion colitis. A prospective, randomised, double-blind, controlled study is carried out.

Methods: Patients who underwent surgery for colorectal carcinoma with protective ileostomy pending reconstructive surgery and with diversion colitis as diagnosis are included. Randomised and divided into two groups. Histological and endoscopic changes were evaluated after stimulation, after restorative surgery and during the short-term follow-up after surgery.

Results: Patients in CG were distributed according to the endoscopic index of severity in pre-stimulation/post-stimulation as follows: severe $n=9 / 9$ (25.7\%), moderate $n=23 / 23$ $(65.7 \%)$, and mild $n=3 / 3$ (8.6\%); compared to the distribution in SG, severe $n=9 / 0$ (26.5/0\%), moderate $n=23 / 3$ (67.6/8.8\%), mild $n=2 / 19$ (5.9/55.9\%) and normal colonoscopy in $0 / 12$ patients (0/35.3\%).

Conclusion: Probiotic stimulation of the efferent loop is a safe and effective method, managing to reduce both macroscopic and microscopic colitis, as well as a decrease in symptoms in the short term after reconstructive surgery.

Keywords: diversion colitis, efferent loop stimulation, ileostomy closure, inflammatory bowel diseases, IBD management, probiotics 


\section{INTRODUCTION}

In Western countries, rectal cancer represents $28-35 \%$ of all colorectal cancers, with an incidence of 15-25 new patients per 100,000 inhabitants/year. Its greatest complication is anastomotic leakage, with an incidence of $25 \%$ (1). The creation of a temporal ileostomy in patients operated on for colorectal carcinoma by means of a low anterior resection with total excision of the mesorectum, reduces the morbidity associated with anastomotic leakage (2). Around $18-40 \%$ of patients will present complications, such as diversion colitis, small bowel obstruction, surgical wound infection, postoperative ileus, anastomotic leak, fistula, perforation, abscess, bleeding, or hernia (3).

Diversion colitis (DC) is an inflammation produced in a defunctionalised segment of the colon after a temporary stoma has been performed (4). Described by Glotzer et al. (5), it is characterised by an inflammation of the large bowel mucosa that mimics idiopathic inflammatory bowel disease (4). It can manifest symptoms such as abdominal or pelvic pain, mucous discharge, tenesmus, fever, and rectal bleeding in the most severe cases, although up to $30 \%$ of patients remain asymptomatic (6). There are several hypotheses to explain the pathogenesis. One of them relates chronic inflammation with a decrease of bacteria in the dysfunctional area $(7,8)$. This inflammation causes endoscopic findings such as mucosal friability, oedema, erythema, appearance of polyps, ulcers, stenosis, and microscopic findings such as lymphoid follicular hyperplasia, infiltration of the lamina propria by lymphocytes, eosinophils, the appearance of plasma cells, architectural disruption, and the appearance of crypt abscesses (4).

The definitive treatment is the restoration of the continuity of the digestive tract $(4,6)$. Pharmacological treatments using instillations with short-chain fatty acids, mesalazine fibre, or corticosteroids are reserved for patients who are not candidates for surgical treatment or for stimulation of the efferent loop prior to surgery $(9,10)$. Stimulation with probiotics prior to closing the protective stoma would allow the dysfunctional colon segment to be repopulated, which would reduce diversionary colitis (11).

Probiotics are defined as live microorganisms that, when administered in adequate amounts, confer a health benefit on the host $(12,13)$. These and their metabolic products have been proposed as food supplements to achieve a healthier intestinal homeostasis and also as a treatment for pathologies with an important inflammatory component. Probiotics interact with the intestinal mucosa, reducing the molecular production of pro-inflammatory substances $(12,14)$. This immunomodulatory effect is what is needed in order to reduce the level of diversion colitis. Currently available probiotics, aimed at other pathologies with inflammatory conditions, produce a modulating effect in a transitory and limited way. This time-limited effect is what is needed to reduce the level of diversion colitis, since after reconstruction this tends to disappear.

\section{MATERIALS AND METHODS}

\section{Study Design}

Prospective, randomised, multicentre, double-blind experimental study, comparing two groups of patients operated on for colorectal carcinoma with protective ileostomy. One group includes patients treated with stimulation of the efferent loop with probiotics prior to transit reconstruction surgery; the other control group is stimulated without giving any substance.

\section{Simple Size}

The sample size was calculated according to the incidence of diversion colitis published in systematic reviews. Assumed reduction in PI was 50\% (100-50\%). With a loss adjustment of $15 \%$, it was necessary to have 30 patients per group. We recruited 34 patients in stimulated group and 35 patients in control group for a statistical level of $95 \%$ and a power of 0.8 .

\section{Selection of Patients}

Between January 2017 and December 2018, all the patients from participating centres included in the surgical waiting list for temporary stoma closure after colorectal carcinoma were consecutively evaluated to determine their inclusion in the study. The selection flowchart of the study patients can be seen in Figure 1.

The inclusion criteria were being over 18 years of age, having protective ileostomy after colorectal carcinoma surgery free of disease, with endoscopic and histological confirmation of diversion colitis and having signed the informed consent. The exclusion criteria being under 18 years of age, clinical history and histological confirmation of inflammatory bowel disease with colorectal involvement and refusal to participate in the study. Abandonment criteria: loss during follow-up, exitus, and anastomotic leakage after stoma closure.

\section{Randomisation and Intervention}

A colonoscopy including biopsies for histological study, was performed on all patients selected to participate in the study. After confirming the diagnosis, level of colitis (based on the Harig scoring system) (15), and excluding patients who did not meet the selection criteria, randomisation was performed. Randomisation was performed by using a computer-generated sequence (Statistical software EPIDAT 4.1) into 2 groups:

- Stimulation group (SG): preoperative stimulation of the distal limb of the ileostomy loop with probiotics was performed during the 20 days prior to surgery every second day. During the process and after it, the patient registers the appearance of symptoms after each stimulation session: abdominal pain, emission of gas, and stool. A sterile Foley catheter No.14 $\mathrm{Ch}$ connected to an infusion set was introduced through the de-functioned bowel to allow the slow infusion of a solution with $4.5 \mathrm{mg}$ of probiotics diluted in $250 \mathrm{ml}$ of $0.9 \%$ physiological saline for 20-30 min. Each preparation was made under sterile conditions and maintaining the cold chain. Vivomixx ${ }^{\circledR}$ lyophilised live bacteria, marketed by MENDES, S.A, contained $4.5 \times 1011$ of live bacteria in each preparation: 


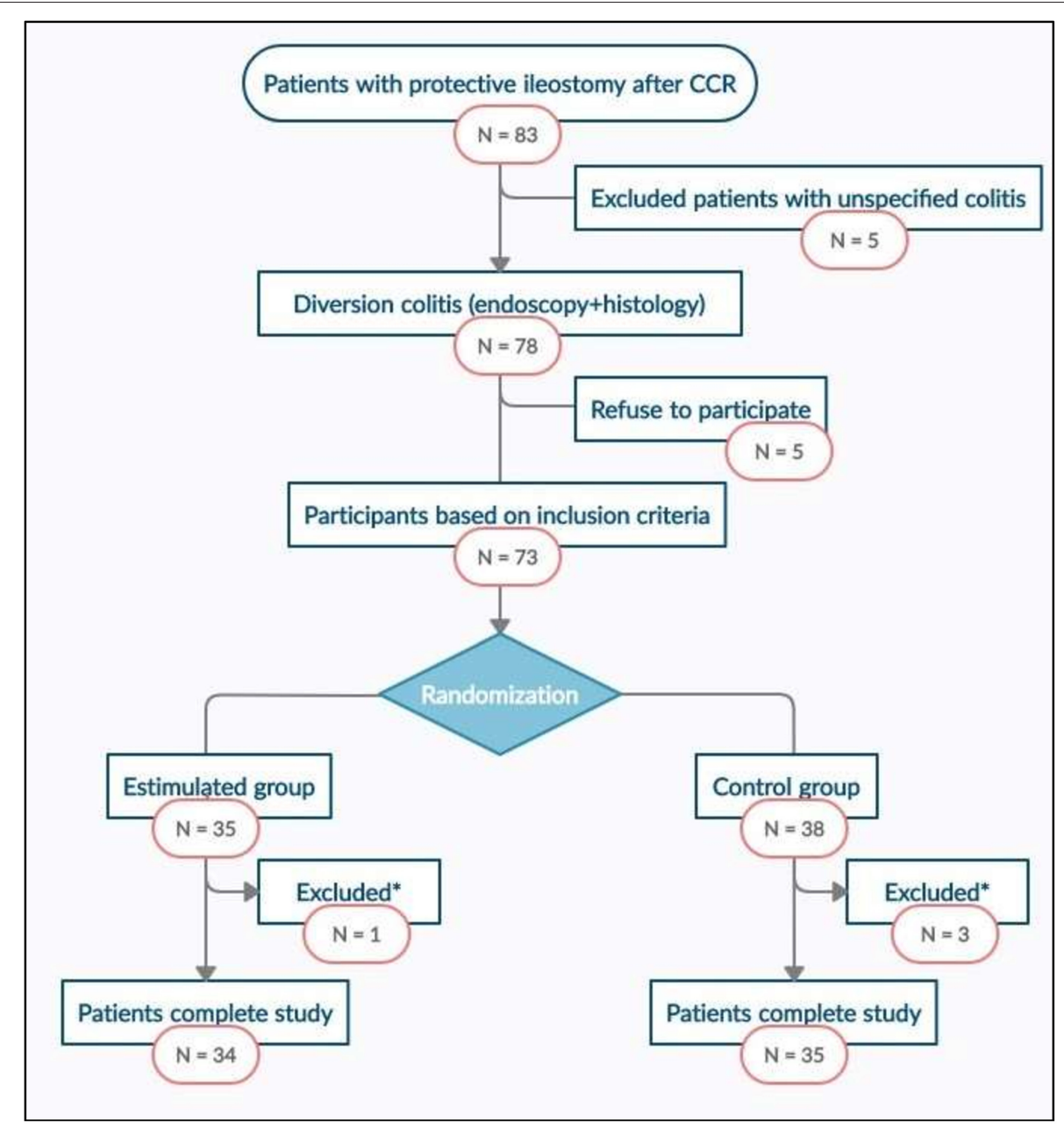

FIGURE 1 | Study flowchart. CRC, Colorrectal cancer. *Excluded patients with anastomic leak.

- Four strains of Lactobacillus:

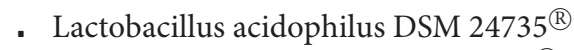

- Lactobacillus plantarum DSM $24730^{\circledR}$

- Lactobacillus paracasei DSM $24733^{\circledR}$

- Lactobacillus delbrueckii subsp. bulgaricus DSM $24734^{\circledR}$

- Three strains of Bifidobacterium:

- Bifidobacterium breve DSM $24732^{\circledR}$

- Bifidobacterium longum DSM $24736^{\circledR}$

- Bifidobacterium infantis DSM $24737^{\circledR}$

- One strain of Streptococcus

- Streptococcus thermophilus DSM $24731^{\circledR}$

- Control group (CG): exactly the same procedure was carried out, but with the infusion set closed. During the process and after it, the patient himself registers the appearance of symptoms after each stimulation session: abdominal pain, emission of gas, and stool.
After ten stimulation sessions, $24 \mathrm{~h}$ before surgery, a colonoscopy with biopsy was performed on all patients, re-quantifying the endoscopic and histological index of severity of diversion colitis.

\section{Surgery and Follow-Up}

All patients were admitted in the hospital the day before surgery, fasting, receiving antithrombotic prophylaxis (enoxaparin $40 \mathrm{mg}$ subcutaneous) and premedication according to the pre-anaesthesia's instructions sheet. The reconstruction surgery was carried out by three expert surgeons from the Colorectal Surgery department. A parastomal incision was made and carried out sharply into the peritoneal cavity. The anastomosis was lateral-lateral, either manual or mechanical, according to the decision of the surgeon. Every surgeon was allowed to decide as well whether to change to a median laparotomy procedure. Complications or events happened during surgery were recorded in the surgical procedure protocol. General anaesthesia was given to all patients and, after extubation and stabilisation in 
the postoperative resuscitation room, they went directly to the hospitalisation ward.

Follow-up during hospitalisation was carried out by the staff of the Colorectal Surgery department of each centre, recording any postoperative complications, with special vigilance of abdominal pain, passage of flatus, or stool with correct quantification and initiation of oral tolerance. Patients were discharged from the hospital after re-establishing intestinal transit, adequate oral tolerance and stool control, recording the length of stay in hospital.

Follow-up after hospitalisation was carried out by Colorectal Surgery team in the first, third, and sixth postoperative months. These evaluations were performed by the colorectal surgeon who intervened in each patient. Any symptomatology related to the intervention was recorded, with special monitoring of abdominal pain and number and control of stools.

\section{Blinding}

To ensure blinding of the patients, all underwent the same diagnostic procedure. During the stimulation sessions, both the solution with probiotics and the infusion set were covered by an opaque protective envelope, which prevented observing the colour and transparency of the fluid, or whether the system was open or closed. The stimulation sessions were performed by a single surgeon, who was also in charge of preparing the dilution.

The endoscopist, the pathologist and the surgeon who performed the surgical intervention and the follow-up, as well as surgeons who participated, after the surgery, in the hospitalisation process, did not know whether the patient had received probiotics or not.

\section{Assessment Criteria}

The main evaluation criterion was the effect caused by stimulation of the efferent loop with probiotics on the persistence and severity index of diversion colitis, both endoscopic and histological, comparing SG and CG after stimulation, after surgery, in the first post-operative month and during short-term follow-up (third and sixth postoperative month).

Secondary evaluation criteria were passage of gas and stool during the stimulation period and after surgery, the initiation of oral tolerance, restoration of intestinal transit (gas and stool), and hospital stay.

\section{Statistical Analysis}

A descriptive univariate analysis of sociodemographic and clinical variables was performed. The Kolmogorov-Smirnov test was used to verify the normality of the quantitative variables. To describe the quantitative variables, the mean and standard deviation were used, and the median and interquartile range for those variables that did not follow a normal distribution. For qualitative variables frequencies and percentages will be used. Afterwards, to verify the main objectives, a bivariate analysis was performed. A contrast test of proportions based on the Chisquare test was used in order to determine whether stimulation of the efferent loop with probiotics prior to the closure of the protective ileostomy reduces the level of diversion colitis, as well as its effects on the passage of gas and stool, the initiation of oral tolerance, re-establishing intestinal transit and hospital stay. To quantify its level of association, Cramer's Phi and V coefficients were calculated. In order to correlate quantitative variables, the Spearman's rank correlation coefficient was used. A $p<0.05$ was considered to be significant. Statistical analysis was performed using the statistical program SPSS version 24.0, with the support of calculation tools provided by the software Microsoft Excel or $\mathrm{R}$.

\section{Ethical Aspects}

The project was performed with the consent of the Ethics Coordinating Committee for Biomedical Research of Andalusia, Spain, and registered with the project number 2017/331191354. Written informed consent was requested to participate in the study, giving details of both the study objectives and the methodology to be followed. The data was kept anonymous, maintaining the confidentiality and anonymity of the participants. The CONSORT Statement criteria for the design of clinical trial were followed (standard trial methodology).

\section{RESULTS}

\section{Study Population}

Between January 2017 and December 2018, 83 disease free patients with protective ileostomy after colorectal carcinoma resection were reviewed and included in the surgical waiting list for intestinal transit reconstruction. Seventy eight of them met the endoscopic and histological criteria for diversion colitis diagnosis and 73 patients were finally randomised into two groups, intervention $(n=35)$ and control $(n=38)$. Sixty nine patients completed the study, 1 of them from SG and 3 from CG abandoning the study because of anastomotic leakage. Study flowchart is presented in Figure 1. There were no significant differences between SG and CG in terms of sociodemographic, clinical, or surgical variables (Table 1).

\section{Main Assessment Criteria}

The effect of stimulation with probiotics on diversion colitis, identified by endoscopic, is showed in Figure 2. It shows a homogeneous distribution in the pre-stimulation phase between SG and CG $(p=0.911)$, with $n=9$ patients with severe diversion colitis in both groups (26.5\% SG vs. $25.7 \% \mathrm{CG}), n=23$ patients with moderate diversion colitis in both groups $(67.6 \%$ SG vs. $65.7 \%$ CG) and $n=2$ patients with mild diversion colitis in SG (5.9\%) vs. $n=3$ patients in CG (8.6\%). In the post-stimulation phase, CG maintains its distribution with $n=9$ patients with severe diversion colitis (25.7\%), $n=23$ patients with moderate diversion colitis (65.7\% CG), and $n=3$ patients with mild diversion colitis (8.6\%); on the other hand, SG shows no patients with severe diversion colitis $(n=0), n=3$ patients with moderate diversion colitis ( $8.8 \% \mathrm{CG}), n=19$ patients with mild diversion colitis (55.9\%) and $n=12$ patients with normal endoscopic findings (35.3\%), achieving a $p<0.001$ and a Phi and V Cramer coefficient of 0.883 .

The effect of stimulation with probiotics identified by histology is showed in Figure 3. It shows a homogeneous distribution in the pre-stimulation phase between SG and CG 
TABLE 1 | Demographics, clinics, and surgical characteristics.

\begin{tabular}{|c|c|c|c|}
\hline & $\begin{array}{l}\text { Stimulated group } \\
\qquad(n=34)\end{array}$ & $\begin{array}{l}\text { Non-stimulated group } \\
\qquad(n=35)\end{array}$ & $p$ \\
\hline \multicolumn{4}{|l|}{ Demographics } \\
\hline Age (years) & $65(45-81)$ & $68(41-80)$ & 0.130 \\
\hline Sex ratio (Men/Women) & $23: 11$ & $25: 10$ & 0.733 \\
\hline $\mathrm{BMI}\left(\mathrm{kg} / \mathrm{m}^{2}\right)$ & $23.5(21.6-32.6)$ & $27.6(18.8-40.2)$ & 0.091 \\
\hline ASA & & & 0.483 \\
\hline ASA I-II & 31 & 30 & \\
\hline ASA III & 3 & 5 & \\
\hline Smoker / Non-smoker & $20 / 14$ & 23/12 & 0.826 \\
\hline \multicolumn{4}{|l|}{ Colorectal surgery } \\
\hline Surgical procedure: & & & 0.129 \\
\hline LAR & 25 & 25 & \\
\hline uLAR & 9 & 10 & \\
\hline Surgical approach: & & & 0.551 \\
\hline Laparoscopic & 24 & 24 & \\
\hline Open & 10 & 11 & \\
\hline Type of anastomosis: & & & 0.430 \\
\hline Stapled EEA & 31 & 33 & \\
\hline Coloanal anastomosis & 3 & 2 & \\
\hline Neoadjuvant therapy & 26 & 25 & 0.239 \\
\hline Adjuvant treatment & 26 & 28 & 0.256 \\
\hline \multicolumn{4}{|l|}{ lleostomy closure } \\
\hline Time between surgery & $12(8-37)$ & $9(6-32)$ & 0.813 \\
\hline Surgery: & & & 0.690 \\
\hline Small bowel resection & 33 & 34 & \\
\hline Ileocecal resection & 1 & 1 & \\
\hline Surgical approach: & & & 0.291 \\
\hline Peri-ileostomy & 30 & 28 & \\
\hline Midline laparotomy & 4 & 7 & \\
\hline Type of anastomosis: & & & 0.355 \\
\hline Sewn & 29 & 29 & \\
\hline Stapled & 5 & 6 & \\
\hline Time (minutes) & $50(30-70)$ & $65(50-120)$ & 0.053 \\
\hline
\end{tabular}

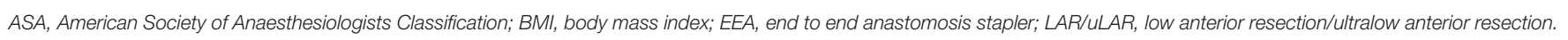

( $p=0.896$ ), with $n=9$ patients with severe diversion colitis in both groups (26.5\% SG vs. $25.7 \%$ CG), $n=23$ in CG and $n=21$ patients with moderate diversion colitis in both groups (61.8\% SG vs. $65.7 \%$ CG) and $n=4$ patients with mild diversion colitis in SG $(11.7 \%)$ vs. $n=3$ patients in CG $(8.6 \%)$. In the poststimulation phase, the CG maintains its distribution with $n=$ 9 patients with severe diversion colitis (25.7\%), $n=23$ patients with moderate diversion colitis (65.7\% CG), and $n=3$ patients with mild diversion colitis $(8.6 \%)$, on the other hand, SG shows no patients with severe diversion colitis $(n=0), n=3$ patients with moderate diversion colitis ( $8.8 \%$ CG), $n=21$ patients with mild diversion colitis $(61.8 \%)$ and $n=10$ patients with normal histologic findings (29.4\%), getting a $p<0.001$ and a Phi and V Cramer coefficient of 0.843 .

Abdominal pain was the only symptom observed during stimulation, which appeared in $20.5 \%$ of patients SG $(n=7)$ compared to $14,3 \% \mathrm{CG}(n=5)$. There were no statistically significant differences between the two groups. Abdominal pain was evaluated using the visual analogue scale (VAS). Pain was moderated in SG, only present in the first stimulation sessions and disappearing afterwards. Pain was mild-moderate in CG in all stimulation sessions and disappeared after their completion.

The symptoms of diversion colitis after reconstruction surgery appeared in $100 \%(n=35)$ of the patients in CG, vs. $23.5 \%$ in SG $(n=8)$, the remaining $76.5 \%$ being asymptomatic after surgery $(n=26)$, with $p<0.001$ and a Phi and V Cramer coefficient 0.789 . This clinical scenario is maintained 1 month after reconstructive surgery in CG, with 94.3\% $(n=33)$ of patients showing symptoms of diversion colitis, compared to $5.7 \%$ who are asymptomatic $(n=2)$. SG shows $97.1 \%$ of asymptomatic patients after surgery $(n=33)$ compared to $2.9 \%$ of patients with diversion colitis $(n=1)$, with $p<0.001$ and a Phi and V coefficient of Cramer 0.913. Finally, during the short-term follow-up after reconstructive surgery, symptoms are 


\section{Diversion colitis: endoscopy}

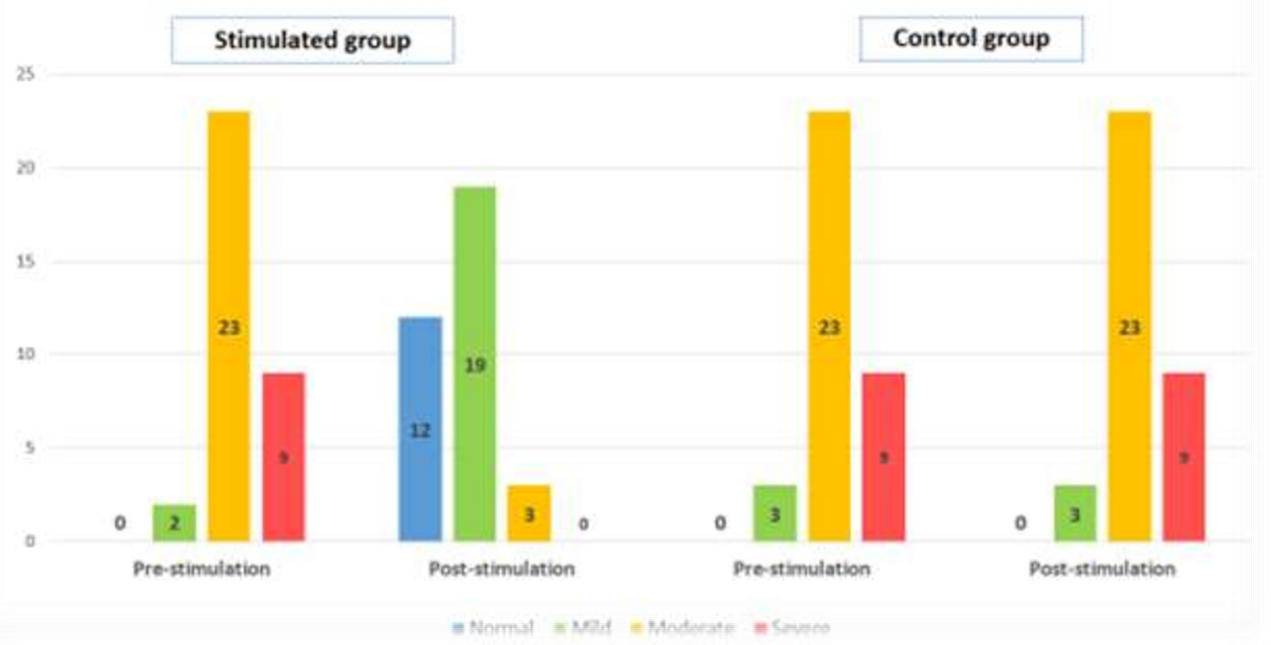

FIGURE 2 | Grade of macroscopic diversion colitis, measured by endoscopy, in the stimulated group and control group, in the pre-stimulation and post-stimulation phases.

\section{Diversion colitis: histology}

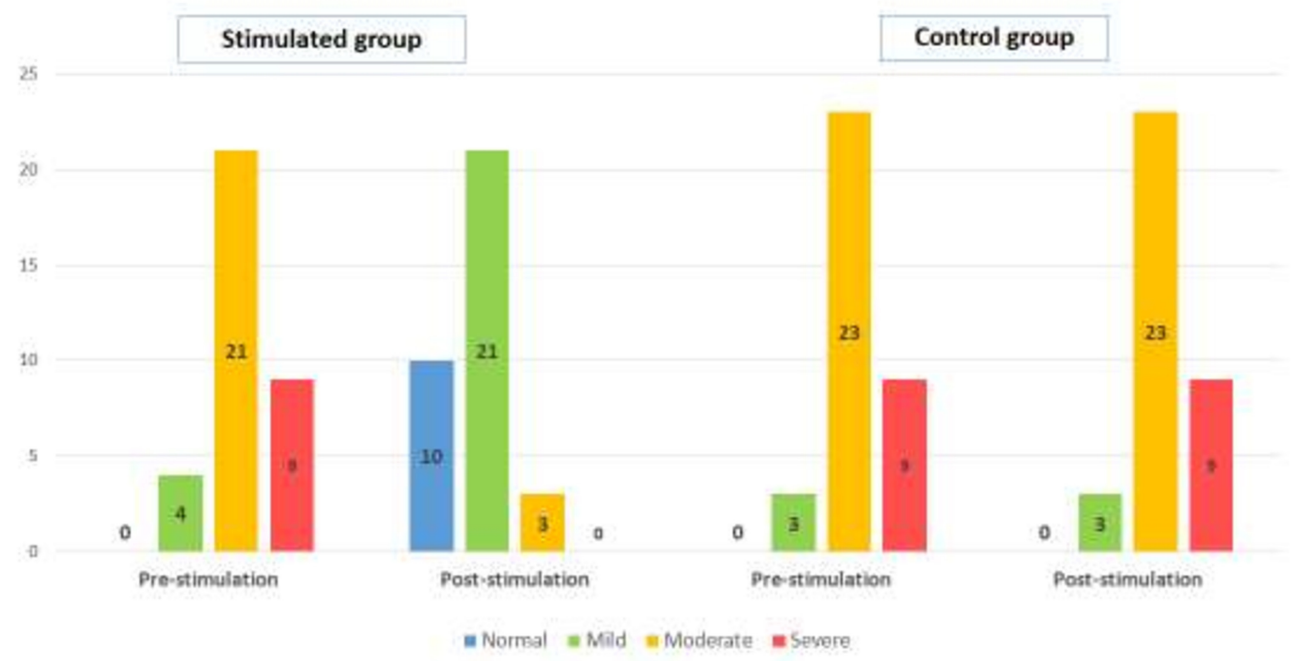

FIGURE 3 | Grade of microscopic diversion colitis, measured by histology, in the stimulated group and control group, in the pre-stimulation and post-stimulation phases.

present in CG with $28.6 \%(n=10)$ compared to $71.4 \%$ who are asymptomatic $(n=25)$. SG shows $100 \%$ asymptomatic patients after surgery, with $p<0.001$ and a Phi and V Cramer coefficient of 0.406 .

\section{Secondary Endpoints}

In the comparative analysis, we found a direct relationship between passage of gas and stool during the stimulation period and the decrease in the level of diversion colitis in SG with $p<0.001$ and a Phi and V Cramer coefficient of 0.683 for stool and 0.971 for gas. There were no statistically significant differences among the initiation of oral tolerance, restoration of intestinal transit, or length of hospital stay, as shown in Table 2. The incidence of postoperative ileus was similar in both groups, appearing in 10/34 (29,4\%) for SG and 11/35 (31.4\%) for CG with $p=0.192$. After reconstructive surgery, SG started oral tolerance 
TABLE 2 | Postoperative results.

\begin{tabular}{|c|c|c|c|}
\hline & $\begin{array}{l}\text { Stimulated group } \\
\qquad(n=34)\end{array}$ & $\begin{array}{l}\text { Non-stimulated group } \\
\qquad(n=35)\end{array}$ & $p$ \\
\hline Postoperative ileus, $n$ (\%) & $10(29.4 \%)$ & $11(31.4 \%)$ & 0.192 \\
\hline Nasogastric tube, n (\%) & $9(26 \%)$ & $11(31.4 \%)$ & 0.116 \\
\hline Time to tolerating a diet, days-mean (range) & $2(1-24)$ & $3(2-50)$ & 0.619 \\
\hline Start of the passage of flatus, days-mean (range) & $2(1-20)$ & $2(1-48)$ & 0.173 \\
\hline
\end{tabular}

The median has been used as a measure of central tendency for the evaluation of variables as initiation of oral tolerance, gas emission, restoration of transit and duration of hospital stay.

$24 \mathrm{~h}$ earlier than CG, but it was statistically non-significant (2 days vs. 3). The emission of gases and the restoration of intestinal transit happened 2 days after surgery in both groups. SG had an interval between 1 and 20 days in the emission of gases and between 1 and 21 days in the intestinal transit, vs. 1-48 days in both cases in CG. The hospital stay was also shorter in the SG, but without statistical significance.

\section{DISCUSSION}

As mentioned in the introduction, colorectal cancer surgery has progressively evolved. More and more complex resections are performed both by abdominal and perineal approach, increasing their quality and achieving a more radical surgery with increasingly inferior anastomoses and without the need for a permanent stoma, even if still requiring a temporary stoma (16). To protect low colorectal anastomosis from possible complications, we must create an ileostomy, which also will lead to morbidity. Derivative stomas are not exempt from complications, the most feared being the anastomotic leak however the most common is diversion colitis $(2,3,17)$. In patients that require a protective ileostomy, dysbiosis happens in the excluded colon segment that leads to diversion colitis (6). This dysbiosis activates metabolic products that produce an immune response, causing an attack on the colonic mucosa and affecting the function of the regulatory immune cells that normally promote its homeostasis (18). This causes structural changes, such as atrophy of villi in the defunctionalised limb, and in consequence produce loss of smooth muscle area and reduced isometric contractility with loss of the intestinal absorption capacity (7). Intestinal dysbiosis has been linked to the pathogenesis of numerous chronic diseases, such as inflammatory bowel disease, and has been studied in order to identify its correction, with variable results $(19,20)$.

The bibliography about diversion colitis and its relationship with microbiota alteration is not extensive. In the last 2 years, two studies have been published about intestinal microbiota $(19,21)$; to which we must add, on the one hand, the latest systematic review on diversion colitis published by Kabir et al. (6) that reviews a total of 3,305 articles, eventually including 35 studies, and analyses the pathophysiology, clinical presentation and treatment of diversion colitis which concludes that there is a great variability of forms of presentation and a single definitive treatment, which is the reconstruction of the transit. Results on preoperative stimulation prior to the closure of the protective ileostomy published by Rombey et al. (10), including 8 studies with a total of 267 patients, despite the promising initial results, show that there is no sufficient quality evidence to recommend routine implementation of preoperative bowel stimulation in clinical practise. That is why we propose that microbial manipulation by stimulating probiotics prior to closing the protective ileostomy would allow the altered autoimmune function to be normalised, restore homeostasis, and reduce mucosal inflammation.

After completing the stimulation phase with probiotics, no statistically significant differences were detected in terms of sociodemographic, clinical or surgical variables. On the contrary, there is indeed a notable decrease in surgical time in SG, which we associate with the thickening of the distal end caused by stimulation and which facilitates the performance of the anastomosis. In the pre-stimulation phase, no differences were found in terms of index of severity in both groups, either by endoscopy or histology. After stimulation, a decrease of the index of severity was observed in SG compared to CG, both by endoscopy and histology, as shown in Figures 2, 3.

A reduction in the level of diversion colitis was achieved by $100 \%$ of SG patients, with the disappearance of macroscopic diversion colitis in $35.3 \%$, obtaining normal endoscopic findings in 12 patients $(p<0.001$ and a Phi and V Cramer coefficient of 0.883 ) and the disappearance of microscopic sign in $29.4 \%$, obtaining normal histological findings in 10 patients $(p<0.001$ and a Phi and V Cramer coefficient of 0.843). Both cases showed a strong correlation between stimulation with probiotics and the decrease of diversion colitis, with the appearance of colicky abdominal pain in $20.5 \%$ of the patients $(n=7)$ as the only sideeffect, valued as moderate pain using the visual analogue scale (VAS) and only associated with the first stimulation sessions, disappearing afterwards. This effect has already been described in studies with stimulation of the efferent loop with short chain fatty acids $(6,10,15)$.

At the same time as stimulation, an increase in stool and gas emission was observed during this phase in SG compared to CG, which we directly relate to a decrease or disappearance of diversion colitis after stimulation with probiotics with a value of $p<0.001$ and a Phi and V Cramer coefficient of 0.683 for stool and 0.971 for gas, both showing the association with a strong correlation. Initiation of intestinal transit prior to reconstruction 
allows the identification of functional obstructions distal to the ileostomy that can cause mechanical ileus after surgery and that can be solved by endoscopic dilations or, on the contrary, it allows the identification of a level of incontinence associated with the anterior resection syndrome, which allows for early toilet training $(22,23)$.

Regarding the effect on bowel function after transit reconstruction, no differences were observed between the two groups, with a non-statistically significant time to recovery of transit and oral tolerance. The difference in terms of hospital stay was 1 day, with a median of 4 days in SG and 5 days in CG, associating it with 24 -h difference in oral tolerance between SG, in which $58 \%$ of patients tolerate liquid diet in the first 24-48 h, compared to the CG, which requires $48-72 \mathrm{~h}$. There were no differences in postoperative ileus between SG $(n=10$, $29.4 \%)$ and CG $(n=11,31.4 \%)$, highlighting a disagreement with systematic reviews published by Rombey and Garfinkle and other studies on post-operative ileus that seem to improve after stimulation of the efferent loop prior to closure of the ileostomy $(7,23-28)$. Nonetheless, both conclude with a lack of evidence to recommend the stimulation of the efferent loop in a routine way and emphasise the need to carry out multicentre studies with higher scientific quality, in order to verify their validity.

The observations presented here demonstrate that the decrease in endoscopic and histological findings associated with the decrease in inflammation means that stimulation of the efferent loop of the ileostomy with probiotics can be an alternative treatment in patients with symptomatic DC who are not candidates for reconstructive surgery as a treatment to resolve the colonic inflammation $(29,30)$. Finally, the stimulation of the efferent loop with probiotics can be an alternative treatment to resolve the inflammation in patients whose surgical option is not feasible.

The most studied probiotic bacterias are Bifidobacterium and Lactobacillus spp. These two produce a decrease of proinflammatory molecules and an increase of molecules that inhibit inflammation, also protecting against oxidative stress in humans and demonstrating an important role in intestinal disbiosis $(7,31,32)$. Currently, the evidence shows that probiotics have a positive effect on systemic and oxidative inflammation, especially at the gastrointestinal level. L. acidophilus, one of the probiotics administered during our stimulation, has demonstrated its role in inflammatory regulation in multiple experimental studies (32-41). A randomised controlled clinical trial conducted by Jafarnejad et al. (42) describes the effect of supplementation with probiotics for 8 weeks, in this case, with VSL3 (a probiotic similar to the one administered in our study), on glycaemic status and inflammatory markers among pregnant women. The probiotic supplements contained eight strains of lactic acid bacteria (S.thermophilus, Bifidobacterium breve, Bifidobacterium longum, Bifidobacterium infantis, L. acidophilus, L. plantarum, L. paracasei, and L. delbrueckii subsp. Bulgaricus). They found a statistically significant decrease in TNF alpha and CRP levels in the probiotic group compared to the placebo. Results are superimposable to other studies (41).

Finally, it was possible to reduce diversion colitis symptoms after reconstructive surgery in $76.5 \%$ of SG $(n=26)$ with $p<0.001$ and observing correlation between the absence of symptoms and stimulation with a V Cramer coefficient of 0.789 , compared to CG, in which $100 \%$ of patients presented symptoms. This is maintained in the follow-up to the first month after closure ileostomy with $94.3 \%$ of symptomatic patients in CG vs. $2.9 \%$ in SG, with $p<0.001$ and an association of 0.913 . However, in the short-term follow-up, both tend to equalise, achieving $100 \%$ asymptomatic patients in SG and $71.4 \%$ in CG, with $p<0.001$ and a Phi and V Cramer coefficient of 0.406. This correlation disappears between the third and sixth month, when diversion colitis becomes non-existent both endoscopically and microscopically. This fact coincides with the transitory and limited modulatory effect that probiotics produces on the intestinal mucosa (43-47) and with the recovery curve of intestinal function published in other studies $(7,9)$. However, as the main limitation of our study has been the sample size we cannot make definitive statements about the effectiveness of this technique. We will need additional multicentre studies on bowel function and preoperative stimulation prior to closure of the protective ileostomy to confirm these conclusions.

\section{CONCLUSION}

The pathogenesis of diversion colitis is related with a chronic inflammation and decrement of flora in the dysfunctional area. The definitive treatment is the restoration of the continuity of the digestive tract, and the stimulation of the efferent loop with probiotics would allow patients to reduce complications in the pre/postoperative process. The stimulation with probiotics is a safe and feasible procedure with minimal adverse effects, being an option for patients who are not candidates for surgical treatment.

\section{DATA AVAILABILITY STATEMENT}

The original contributions presented in the study are included in the article/Supplementary Material, further inquiries can be directed to the corresponding authors.

\section{ETHICS STATEMENT}

The project was performed with the consent of the Ethics Coordinating Committee for Biomedical Research of Andalusia, Spain, and registered with the project number 2017/331191354. The patients/participants provided their written informed consent to participate in this study.

\section{AUTHOR CONTRIBUTIONS}

ÁR-P, GM-M, RP-Q, RR-M, JG-S, and CR-F: conceptualisation, data curation, formal analysis, investigation, methodology, resources, writing-original draught, and writing-review and editing. ÁR-P, GM-M, and RP-Q: project administration. GM-M: software. RP-Q, JG-S, and CR-F: supervision. RR-M and JG-S: validation. GM-M, RP-Q, JG-S, and CR-F: visualisation. All authors contributed to the article and approved the submitted version. 


\section{REFERENCES}

1. Glynne-Jones R, Wyrwicz L, Tiret E, Brown G, Rödel C, Cervantes A, et al. ESMO clinical practice guidelines for diagnosis, treatment and follow-up. Ann Oncol. (2017) 28(Suppl 4):vi22-40. doi: 10.1093/annonc/mdx224

2. Matthiessen P, Hallbook O, Rutegard J, Simert G, Sjodahl R. Defunctioning stoma reduces symptomatic anastomotic leakage after low anterior resection of the rectum for cancer: a randomized multicenter trial. Ann Surg. (2007) 246:207-14. doi: 10.1097/SLA.0b013e3180603024

3. Sharma A, Deeb AP, Rickles AS, Iannuzzi JC, Monson JRT, Fleming FJ. Closure of defunctioning loop ileostomy is associated with considerable morbidity. Colorectal Dis. (2013) 15:458-62. doi: 10.1111/codi.12029

4. Szczepkowski M, Banasiewicz T, Kobus A. Diversion colitis 25 years later: the phenomenon of the disease. Int J Colorectal Dis. (2017) 32:1191-6. doi: 10.1007/s00384-017-2802-z

5. Glotzer DJ, Glick ME, Goldman H. Proctitis and colitis following diversion of the fecal stream. Gastroenterology. (1981) 80:438-41. doi: 10.1016/0016-5085(81)90003-2

6. Kabir SI, Kabir SA, Richards R, Ahmed J, MacFie J. Pathophysiology, clinical presentation and management of diversion colitis: a review of current literature. Int J Surg. (2014) 12:1088-92. doi: 10.1016/j.ijsu.2014.08.350

7. Beamish EL, Johnson J, Shaw EJ, Scott NA, Bhowmick A, Rigby RJ. Loop ileostomy -mediated fecal stream diversion is associated with microbial dysbiosis. Gut Microbes. (2017) 8:467-78. doi: 10.1080/19490976.2017.1339003

8. Williams L, Armstrong MJ, Finan P, Sagar P, Burke D. The effect of faecal diversion on human ileum. Gut. (2007) 56:796-801. doi: 10.1136/gut.2006.102046

9. Keane C, Park J, Öberg S, Wedin A, Bock D, Grady G, et al. Functional outcomes from a randomized trial of early closure of temporary ileostomy after rectal excision for cancer. Br J Surg. (2019) 106:645-52. doi: 10.1002/bjs.11092

10. Rombey T, Panagiotopoulou IG, Hind D, Fearnhead NS. Preoperative bowel stimulation prior to ileostomy closure to restore bowel function more quickly and improve postoperative outcomes: a systematic review. Colorectal Dis. (2019) 21:994-1003. doi: 10.1111/codi.14636

11. Shen Z, Zhu C, Quan Y, Yang Z, Wu S, Luo W, et al. Relationship between intestinal microbiota and ulcerative colitis: mechanisms and clinical application of probiotics and fecal microbiota transplantation. World $J$ Gastroenterol. (2018) 24:5-14. doi: 10.3748/wjg.v24.i1.5

12. Biagioli M, Capobianco D, Carino A, Marchianò S, Fiorucci C, Ricci P, Distrutti E, et al. Divergent effectiveness of multispecies probiotic preparations on intestinal microbiota structure depends on metabolic properties. Nutrients. (2019) 11:325. doi: 10.3390/nu11020325

13. Hill C, Guarner F, Reid G, Gibson GR, Merenstein DJ, Pot B, et al. Expert consensus document. the international scientific association for probiotics and prebiotics consensus statement on the scope and appropriate use of the term probiotic. Nat Rev Gastroenterol Hepatol. (2014) 11:506-14. doi: 10.1038/nrgastro.2014.66

14. Corridoni D, Pastorelli L, Mattioli B, Locovei S, Ishikawa D, Arseneau $\mathrm{KO}$, et al. Probiotic bacteria regulate intestinal epithelial permeability in experimental ileitis by a TNF-dependent mechanism. PLoS ONE. (2012) 7:e42067. doi: 10.1371/journal.pone.0042067

15. Harig JM, Soergel KH, Komorowsky RA, Wood CM. Treatment of diversion colitis with short-chain-fatty acid irrigation. N Eng J Med. (1989) 320:23-8. doi: 10.1056/NEJM198901053200105

16. Heald RJ, Santiago I, Pares O, Carvalho C, Figueiredo N. The perfect total mesorectal excision obviates the need for anything else in the management of most rectal cancers. Clin Colon Rectal Surg. (2017) 30:324-32. doi: 10.1055/s-0037-1606109

17. Farag S, Rehman S, Sains P, Baig MK, Sajid MS. Early vs delayed closure of loop defunctioning ileostomy in patients undergoing distal colorectal resections: an integrated systematic review and meta-analysis of published randomized controlled trials. Colorectal Dis. (2017) 19:1050-7. doi: 10.1111/codi.13922

18. Macfarlane GT, Macfarlane S. Bacteria, colonic fermentation, and gastrointestinal health. J AOAC Int. (2012) 95:50-60. doi: 10.5740/jaoacint.SGE_Macfarlane
19. Mishima Y, Sartor RB. Manipulating resident microbiota to enhance regulatory immune function to treat inflammatory bowel diseases. $J$ Gastroenterol. (2020) 55:4-14. doi: 10.1007/s00535-019-01618-1

20. Lloyd-Price J, Arze C, Ananthakrishnan AN, Schirmer M, Avila-Pacheco J, Poon TW, et al. Multi-omics of the gut microbial ecosystem in bowel diseases. Nature. (2019) 569:655-62. doi: 10.1038/s41586-019-1237-9

21. Knox NC, Forbes JD, Van Domselaar G, Bernstein CN. The gut microbiome as a target for IBD treatment: are we there yet? Curr Treat Options Gastroenterol. (2019) 17:115-26. doi: 10.1007/s11938-019-00221-w

22. Kim KH, Yu CS, Yoon YS, Yoon SN, Lim SB, Kim JC. Effectiveness of biofeedback therapy in the treatment of anterior resection syndrome after rectal cancer surgery. Dis Colon Rectum. (2011) 54:1007-13. doi: 10.1097/DCR.0b013e318221a934

23. Abrisqueta J, Abellan I, Lujan J, Hernandez Q, Parrilla P. Stimulation of the efferent limb before ileostomy closure: a randomized clinical trial. Dis Colon Rectum. (2014) 57:1391-6. doi: 10.1097/DCR.0000000000000237

24. Garfinkle R, Savage P, Boutros M, Landry P, Reynier P, Morin N, et al. Incidence and predictors of postoperative ileus after loop ileostomy closure: a systematic review and meta-analysis. Surg Endosc. (2019) 33:2430-43. doi: 10.1007/s00464-019-06794-y

25. Menéndez P, Garcia A, Lozano E, Pelaez R. Effectiveness of afferent loop stimulation prior to ileostomy closure. Cir Esp. (2013) 91:547-8. doi: 10.1016/j.cireng.2013.11.007

26. Vázquez-Melero A, Loizate-Totoricaguena A, García-Alonso P. Stimulation of the Efferent Loop Before Loop Ileostomy closure. U.S. National Library of Medicine, Bethesda (Maryland, USA). ClinicalTrials.gov Identifier: NCT03424447 (2018).

27. Fernández-López F, González López J, Paz Novo M, Ladra González MJ, Paredes Cotoré J. Estimulación preoperatoria del asa eferente de la ileostomía con ácidos grasos de cadena corta. Cir Esp. (2019) 97:54-6. doi: 10.1016/j.ciresp.2018.06.018

28. Garfinkle R, Trabulsi N, Morin N, Phang T, Liberman S, Feldman L, et al. Study protocol evaluating the use of bowel stimulation before loop ileostomy closure to reduce postoperative ileus: a multicenter randomized controlled trial. Colorectal Dis. (2017) 19:1024-9. doi: 10.1111/codi.13720

29. Rodríguez-Padilla Á, Morales-Martín G, Pérez-Quintero R, GómezSalgado J, Rada-Morgades R, Ruiz-Frutos C. Diversion Colitis: macro and microscopic findings after probiotics stimulation. Biology. (2021) 10:303. doi: 10.3390/biology10040303

30. Rodríguez-Padilla Á, Morales-Martín G, Pérez-Quintero R, GómezSalgado J, Balongo-García R, Ruiz-Frutos C. Postoperative Ileus after stimulation with probiotics before ileostomy closure. Nutrients. (2021) 13:626. doi: 10.3390/nu13020626

31. Morgan DM, Cao Y, Miller K, McGoldrick J, Bellavance D, Chin SM, et al. Microscopic colitis is characterized by intestinal dysbiosis. Clin Gastroenterol Hepatol. (2020) 18:984-6. doi: 10.1016/j.cgh.2019.06.035

32. Rossi M, Amaretti A. Chapter 6: Probiotic properties of bifidobacteria. In: van Synderen D, Mayo B, editors. Bifidobacteria: Genomics and Molecular Aspects. Norfolk: Caister Academic Press (2010). p. 97-123.

33. Buanaim RP, Pereira JA, Campos FG, Kotze PG, Goto EFK, Mendonça RLS, et al. Effects of anti-TNF- $\alpha$ in experimental diversion colitis. Acta Cir Bras. (2019) 34: e201901004. doi: 10.1590/s0102-865020190100000004

34. Biagioli M, Laghi L, Carino A, Cipriani S, Distrutti E, Marchianò $\mathrm{S}$, et al. Metabolic variability of a multispecies probiotic preparation impacts on the anti-inflammatory activity. Front Pharmacol. (2017) 8:505. doi: 10.3389/fphar.2017.00505

35. Hod K, Sperber AD, Ron Y, Boaz M, Dickman R, Berliner S, et al. A doubleblind, placebo-controlled study to assess the effect of a probiotic mixture on symptoms and inflammatory markers in women with diarrhea-predominant IBS. Neurogastroenterol Motil. (2017) 29:e13037. doi: 10.1111/nmo.13037

36. Tenorio-Jiménez C, Martínez-Ramírez MJ, Del Castillo-Codes I, ArraizaIrigoyen C, Tercero-Lozano $\mathrm{M}$, Camacho J, et al. Lactobacillus reuteri V3401 reduces inflammatory biomarkers and modifies the gastrointestinal microbiome in adults with metabolic syndrome: the PROSIR study. Nutrients. (2019) 11:1761. doi: 10.3390/nu11081761

37. Yang YJ, Chuang CC, Yang HB, Lu CC, Sheu BS. Lactobacillus acidophilus ameliorates $\mathrm{H}$. pylori-induced gastric inflammation by inactivating 
the Smad7 and NFkappaB pathways. BMC Microbiology. (2012) 12:38. doi: 10.1186/1471-2180-12-38

38. Borthakur A, Bhattacharyya S, Kumar A, Anbazhagan AN, Tobacman JK, Dudeja PK. Lactobacillus acidophilus alleviates platelet-activating factorinduced inflammatory responses in human intestinal epithelial cells. PLoS ONE. (2013) 8:e75664. doi: 10.1371/journal.pone.0075664

39. Li H, Zhang L, Chen L, Zhu Q, Wang W, Qiao J. Lactobacillus acidophilus alleviates the inflammatory response to enterotoxigenic Escherichia coli K88 via inhibition of the NF-kappaB and p38 mitogen-activated protein kinase signaling pathways in piglets. BMC Microbiol. (2016) 16:273. doi: 10.1186/s12866-016-0862-9

40. Stenman LK, Waget A, Garret C, Klopp P, Burcelin R, Lahtinen S. Potential probiotic Bifidobacterium animalis ssp. lactis 420 prevents weight gain and glucose intolerance in diet-induced obese mice. Benef Microbes. (2014) 5:43745. doi: 10.3920/BM2014.0014

41. Hajifaraji M, Jahanjou F, Abbasalizadeh F, Aghamohammadzadeh N, Abbasi MM, Dolatkhah N. Effect of probiotic supplements in women with gestational diabetes mellitus on inflammation and oxidative stress biomarkers: a randomized clinical trial. Asia Pac J Clin Nutr. (2018) 27:581-91. doi: 10.6133/apjcn.082017.03

42. Jafarnejad S, Saremi S, Jafarnejad F, Arab A. Effects of a multispecies probiotic mixture on glycemic control and inflammatory status in women with gestational diabetes: a randomized controlled clinical trial. J Nutr Metab. (2016) 2016:5190846. doi: 10.1155/2016/5190846

43. Sartor RB, Wu GD. Roles for intestinal bacteria, viruses, and fungi in pathogenesis of inflammatory bowel diseases and therapeutic approaches. Gastroenterology. (2017) 152:327-39. doi: 10.1053/j.gastro.2016.10.012
44. Cohen LJ, Cho JH, Gevers D, Chu H. Genetic factors and the intestinal microbiome guide development of microbe-based therapies for inflammatory bowel diseases. Gastroenterology. (2019) 156:2174-89. doi: 10.1053/j.gastro.2019.03.017

45. Kang SI, Oh HK, Kim MJ, Son IT, Kim DW, Kang SB. The effect of probiotics (CJLP243) on bowel function restoration after ileostomy closure in patients with rectal cancer: a pilot randomised controlled trial. Colorectal Dis. (2016) 18(Suppl 1):127. doi: 10.1111/codi.15463

46. Basso PJ, Câmara NOS, Sales-Campos H. Microbial-based therapies in the treatment of inflammatory bowel disease-an overview of human studies. Front Pharmacol. (2018) 9:1571. doi: 10.3389/fphar.2018.01571

47. Amoroso C, Perillo F, Strati F, Fantini M, Caprioli F, Facciotti F. The role of gut microbiota biomodulators on mucosal immunity and intestinal inflammation. Cells. (2020) 9:1234. doi: 10.3390/cells9051234

Conflict of Interest: The authors declare that the research was conducted in the absence of any commercial or financial relationships that could be construed as a potential conflict of interest.

Copyright (c) 2021 Rodríguez-Padilla, Morales-Martín, Pérez-Quintero, RadaMorgades, Gómez-Salgado and Ruiz-Frutos. This is an open-access article distributed under the terms of the Creative Commons Attribution License (CC BY). The use, distribution or reproduction in other forums is permitted, provided the original author(s) and the copyright owner(s) are credited and that the original publication in this journal is cited, in accordance with accepted academic practice. No use, distribution or reproduction is permitted which does not comply with these terms. 